\title{
Home-based exercise therapy for treating non- specific chronic low back pain
}

\author{
(iD) Michel Kanas ${ }^{1}$ \\ René Souza Faria ${ }^{2}$ \\ Lucas Gabriel Salles ${ }^{3}$ \\ Isabel Cristina Esposito Sorpreso ${ }^{4}$ \\ (iD) Délio Eulálio Martins ${ }^{5}$ \\ Ronaldo Alves da Cunha \\ (iD) Marcelo Wajchenberg ${ }^{5}$
}

1. Assistant Physician of the Spine Clinic of the Sports Injury Center of the Department of Orthopedics and Traumatology at Unifesp/EPM - São Paulo (SP), Brasil. Doctor at the Albert Einstein Israelite Hospital, São Paulo (SP), Brasil. 2. Sports Physical Therapist at the Center of Sports Traumatology of the Department of Orthopedics and Traumatology of Unifesp/EPM - São Paulo (SP), Brasil. 3. Assistant Physical Therapist of the Spine Clinic of the Sports Injury Center of the Department of Orthopedics and Traumatology at Unifesp/EPM - São Paulo (SP), Brasil.

4. Assistant Physician of the Department of Obstetrics and Gynecology, Hospital das Clínicas, Faculty of Medicine, São Paulo University - USP - São Paulo (SP), Brasil. 5. Medical Doctor at the Department of Orthopedics and Traumatology of Unifesp/EPM - São Paulo (SP), Brasil. Doctor at the Albert Einstein Israelite Hospital, São Paulo (SP), Brasil. 6. Assistant Physical Therapist of the Sports Injury Center of the Department of Orthopedics and Traumatology at Unifesp/EPM - São Paulo (SP), Brasil.

http://dx.doi.org/10.1590/1806-9282.64.09.824

\section{SUMMARY}

OBJECTIVE: To evaluate pain, functional capacity, and quality of life of patients with non-specific chronic low back pain, after homebased exercise therapy with different kinds of supervision.

METHOD: Thirty individuals of both gender, between 18 and 65 years old, performed the proposed exercises three times a week, for eight weeks. Group A ( $N=17)$ performed the exercises after a single supervised session. Group $B(N=13)$ was supervised once a week at the rehabilitation center. Both groups received a booklet with instructions, and questionnaires to evaluate pain, functional capacity and quality of life; during the initial evaluation, after four and eight weeks.

RESULTS: There was an improvement in pain and functional capacity between the initial evaluation and week 4, and the initial evaluation and week 8 in both groups ( $p<0.05$ ). In the quality of life evaluation, the criteria for pain, functional capacity, and physical aspects had significant improvement after 8 weeks $(p<0.05)$. There was no difference when comparing groups $A$ and $B(p>0,05)$.

CONCLUSION: Home-based exercise therapy, when performed in a period of eight weeks, using the booklet, was effective for improving level of pain, functional capacity, and quality of life in patients with non-specific chronic low back pain. The weekly supervision did not significantly influence the final outcome between the groups.

KEYWORDS: Low back pain. Exercise therapy. Paraspinal muscles. Abdominal muscles.

DATE OF SUBMISSION: 02-Feb-2018

DATE OF ACCEPTANCE: 16-Feb-2018

CORRESPONDING AUTHOR: Michel Kanas

Av. Onze de Junho, 1266, AP. 184 - 04041-004 -

São Paulo/SP Brasil.

E-mail: michelkanas@gmail.com 


\section{INTRODUCTION}

Non-specific chronic low back pain (NSCLP) is defined by a symptom of pain or discomfort from the lower costal arches to the gluteal sulcus that lasts for at least 12 weeks and may be accompanied by irradiation to the lower limbs. The unspecific nature of the symptom may be related to a muscle-ligament source, associated with quality of life, psychological, or physical factors. However, it is not possible to state with full certainty the anatomical structure responsible for the symptom. ${ }^{1,2}$

The dysfunction of back muscles responsible for stabilization and coordination is considered to be the primary cause for NSCLP. ${ }^{3,4}$ Poor muscle resistance and changes in the neuromuscular control affect the stability of the trunk, the efficiency of movement, and the balance of the entire local musculature, which can lead to a mechanical overload in other structures, such as discs, facet joints, vertebral body, an adjacent muscle groups.

Prescription of supervised exercises is recommended as first-line treatment for NSCLP. However, the availability of secondary rehabilitation centers in the public health system is insufficient to meet the demand of these patients. ${ }^{6,7}$

Since NSCLP cases do not present neurological deficit or clinical signs indicative of fracture, tumor, or infection, they are considered less severe and qualify for treatment in Basic Health Units, with a multi-professional approach by means of ergonomics guidance, posture training, workplace, and home exercises. The major challenge with that type of intervention is the adherence and discipline of the patients to the proposed treatment, with no supervision., ${ }^{7,9}$

The objective of this study was to assess the pain, functional capacity, and quality of life of patients with non-specific chronic low back pain after a home exercise program.

\section{METHODOLOGY}

\section{Study design}

A non-randomized clinical trial with unblinded assessment, conducted from April 2016 to April 2017 at the Spine Clinic of the Sports Injury Center of the São Paulo Federal University, Brazil (Cete-Unifesp).

The study was approved by the research ethics committee, $N^{\circ}$ CEP: 1527/2015, registered under Universal Trial Number (UTN): U1111-1185-1871.

\section{Sample size calculation}

The sample size calculation was based on a pilot study conducted with 14 individuals, eight of them part of Group A (home) and six part of Group B (weekly supervision).

A significant improvement in the Roland Morris scale, between the initial assessment and after eight weeks, was chosen as the primary parameter for the sample size calculation.

Using the sample size calculation formula for paired means, with bilateral significance threshold set at $5 \%$ and a power of $99 \%$, we found significant variation only in Group A, and it was necessary to have at least 12 individuals in Group B to show significant variation. ${ }^{10}$

\section{Population}

Thirty patients with NSCLP from the Spine Clinic were selected, after a medical assessment, to participate in the study.

The inclusion criteria were: age between 18 and 65 years; both gender; having lumbar pain with no specific cause for over 12 weeks; having front and lateral lumbosacral x-rays; agree to participate in the study by reading and signing the informed consent form (ICF).

The exclusion criteria were: pregnancy; radiographic changes (fractures, deformities, spondylolisthesis, and tumors); prior surgical procedure in the spine; clinical symptoms of neural compression; any other disease that can cause back pain.

\section{Intervention}

After the initial medical assessment and inclusion into the study, the participants were arranged in two unblinded groups, according to their availability to get to the Rehabilitation Center: Group A ( $\mathrm{N}=17)$, exercise therapy with no weekly supervision; and Group B (N=13) with weekly supervision.

Patients in both groups carried out exercise therapy for eight weeks. Each session included 10 minutes of aerobic activity (walking or stationary bicycle), followed by five types of muscle stretches and eight types of ground exercises aimed at strengthening the lumbar muscles responsible for stabilization (Figure 1).

After initial guidance, individuals in Group A carried out three home training sessions, unsupervised, for each week. Individuals in Group B also carried out three sessions per week - two at home and one 
supervised by the physical therapist at the rehabilitation center. Both groups received a booklet with instructions.

\section{Data collection instruments}

The participants of the study filled out the Pain Numerical Rating Scale - PNRS, Roland Morris $(\mathrm{RM})^{11}$ and Short Form-36 (SF-36) ${ }^{12}$ questionnaires, translated and validated into Portuguese, at the initial assessment and after four and eight weeks.

In order to control adhesion, the participants were instructed to take note on the booklet of the dates when the sessions were carried out.

\section{Statistical analysis}

The scores from the questionnaires were analyzed using models of generalized estimating equation (GEE) ${ }^{13}$, considering the relationship between the different assessments of the same patient. We included in these models the effects of the exercises in the group (A or B), the time of assessment (initial, week 4 , and week 8 ), and the interaction between group/time.

The results were presented through estimated means with confidence intervals of 95\% (CI95\%). The comparison between groups and times of assessment were presented through estimated mean differences and its respective CI95\%, and $p$ values were corrected using Bonferroni.

The models were adjusted with Normal, Gamma, or Poisson distribution, seeking to find the one that provided lower residuals. The analyses were conducted using the SPSS $^{\circledR}$ software, version 18 , with the significance level set at $5 \%$.

\section{RESULTS}

Individuals in Group B were more assiduous to the home exercise sessions prescribed - they carried out an average of 13.6 of the 16 sessions; participants in Group B carried out an average of 13.9 out of 24 . There was a higher proportion of male individuals in Group A (12M:5F), in relation to Group B (6M:7F).

After analyzing the scores from the Pain Numerical Rating Scale (PNRS), we found evidence of reduction in scores between the initial assessment and week 4 in groups A ( $p=0.036)$ and B ( $p=0.025)$, and between the initial assessment and week 8 in groups A ( $\mathrm{p}=0.036)$ and $\mathrm{B}(\mathrm{p}<0.001)$ (Table 1$)$.

As for the score from the Roland Morris Scale
FIGURE 1: HOME EXERCISE PROGRAM BOOKLET (FRONT), DESCRIPTION OF THE STRETCHES AND MUSCLE-RECRUITMENT EXERCISES.

\section{AEROBICS: WALKING OR STATIONARY BIKE FOR 10 MINUTES}

\section{STRETCHES}
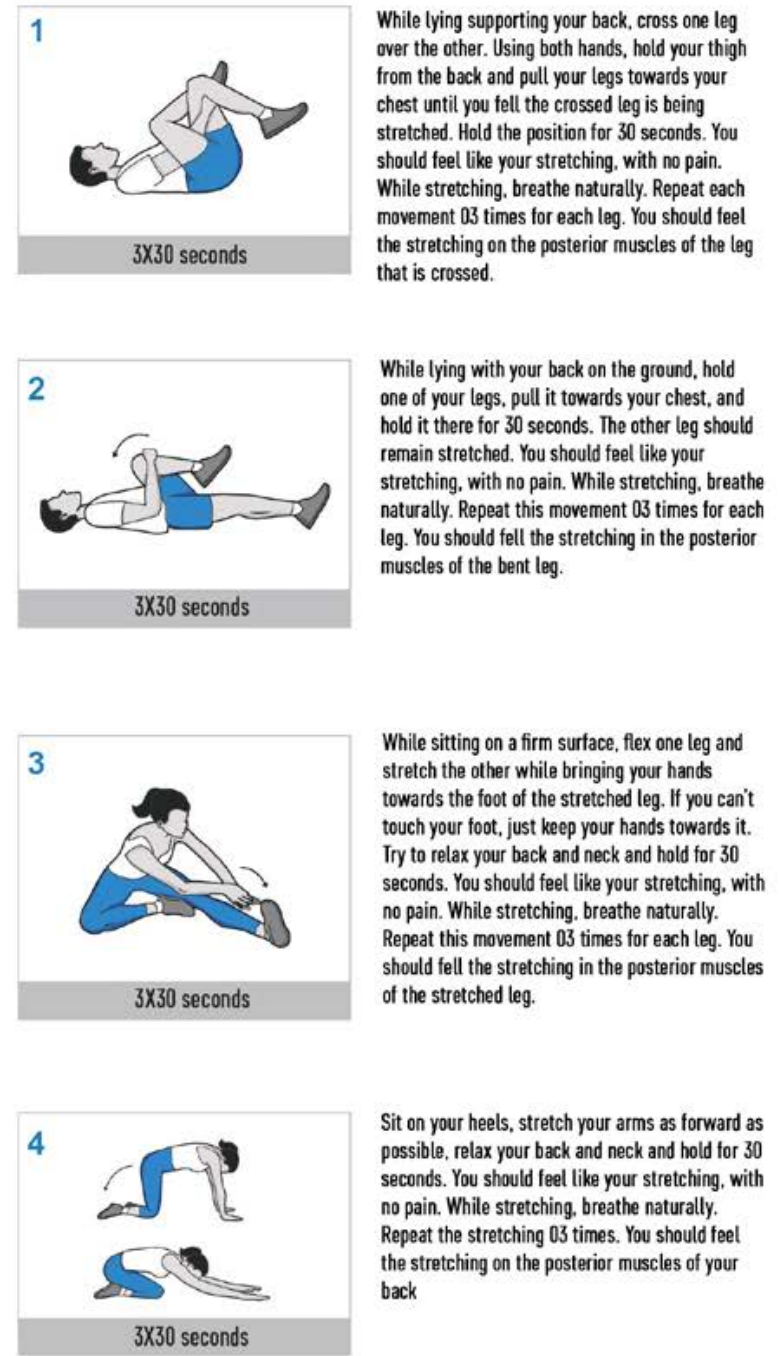

Sit on your heels, stretch your arms as forward as possible, relax your back and neck and hold for 30 seconds. You should feel like your stretching, with no pain. While stretching, breathe naturally. Repeat the stretching 03 times. You should feel the stretching on the posterior muscles of your back

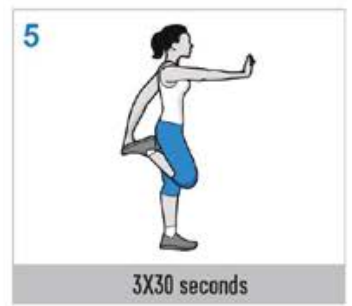

Standing up. use your hand to pull one of your feet towards your glutes and hold for 30 seconds. Remember to use your free hand to support yourself and keep your back as straight as possible. You should feel like your stretching. with no pain. While stretching, breathe naturally. Repeat each movement 03 times for each leg. You should fell the stretching in the anterior muscles of the bent leg. 


\section{MUSCLE-RECRUITMENT}

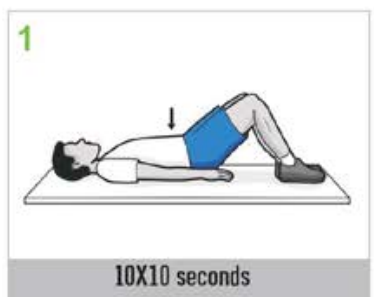

2

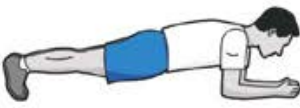

$3 \times 30$ seconds ( 15 seconds min.)

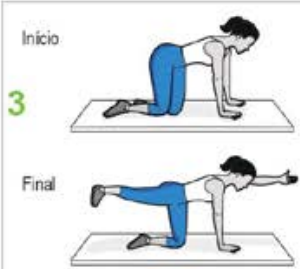

$3 \times 30$ seconds ( 15 seconds min.)

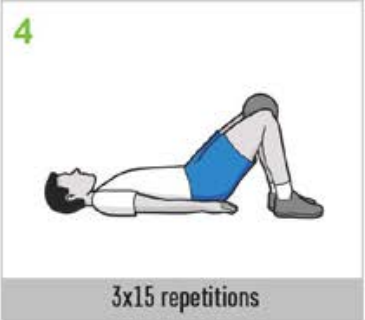

Lying down with your back well-supported, bend your knees and keep your shoulders relaxed. Using your abdomen muscles (without putting to much strength in them), pull in your navel as if trying to make it touch the ground. Once it is pulled in, hold the position for 10 seconds. Repeat the movernent 10 times a day.

Lie on your stomach with your forearms resting on the ground and your elbows well below your shoulders. Carry out exercise 01 (pull navel in) and lift your knees off the floor until they are straight. Keep your back straight and hold that position for $15-30$ seconds (as long as you can). If it is too difficult, keep your knees on the ground and just raise your hips, keeping your back straight. It is important that you maintain your abdomen contracted and your nave pulled in for the entire duration of the exercise. Repeat the movement 03 times.

On a surface that is comfortable for your knees, position yourself on your hands and knees, keeping your back straight. Carry out exercise 01 (pull navel in) and then straighten the left knee up to your hips and the right arm up to your shoulders. Hold the position for 15-30 seconds (as long as you can). Return to the initial position. Straighten the right knee and the left arm and hold for another $15-30$ seconds. It is important that you maintain your abdomen contracted and your navel pulled in for the entire duration of the exercise. Repeat the exercise 03 times.

While lying with your back

well-supported, bend your knees. Place a soft ball or pillow between your legs and press it while, at the same time,

tightening the pelvic muscles, as if trying to "hold in pee."

It is important to "hold in pee" every time you press the ball between your knees. Carry out 03 series of 15 repetitions.

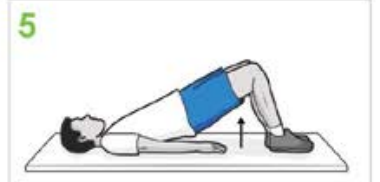

Lie on your back with your knees bent. Carry out exercise 01 (pull navel in) and raise your hips until your back is straight, forming a line between your knees and shoulders. Hold the position for 15-30 seconds (as long as you can). It is important that you maintain your abdomen contracted and your navel pulled in for the entire duration of the exercise. Repeat the movement 03 times.

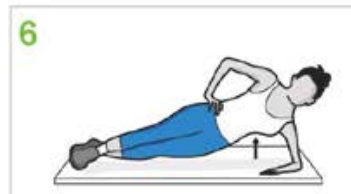

$3 \times 30$ seconds ( 15 seconds min.)

Lying on your side with your elbow aligned with your shoulder and your forearm resting on the ground, carry out exercise 01 (pull navel in) and raise your hips until your body is well stretched, forming a line from your feet to your shoulder. Hold that position for $15-30$ seconds (as long as you can). It is important that you maintain your abdomen contracted and your navel pulled in for the entire duration of the exercise. Repeat this movement 03 times for each side.

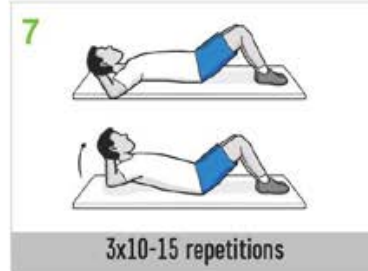

Lying on your back, bend your knees and put your hands behind your head, raising your trunk until your shoulders are off the ground. Try to keep your back on the ground while doing this exercise.

Carry out 03 series of 10 or 15 repetitions.

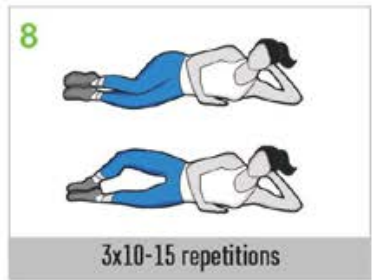

Lying on your side with your knees bent. move your knees away from each other by rotating or opening and closing or legs.

It is important that you keep your feet together during the exercise. Repeat the exercise on both sides, with 03 series of 5 repetitions. 
TABLE 1. ANALYSIS BETWEEN GROUPS: ESTIMATED MEANS AND CONFIDENCE INTERVALS OF 95\% FOR OUTCOMES IN THE INITIAL, WEEK 4, AND WEEK 8 ASSESSMENTS

\begin{tabular}{|c|c|c|c|c|}
\hline Variables & Group A N= 17 & p & Group B N=13 & p \\
\hline \multicolumn{5}{|l|}{ PNRS } \\
\hline Baseline and 4 weeks & $0.9(0.3 ; 1.5)$ & $p=0.036$ & $1.7(0.5 ; 2.8)$ & $p=0.025$ \\
\hline Baseline and 8 weeks & $1.5(0.5 ; 2.4)$ & $p=0.011$ & $2.0(1.2 ; 2.8)$ & $p<0.001$ \\
\hline 4 weeks and 8 weeks & $0.6(-0.1 ; 1.3)$ & $p=0.521$ & $0.3(-0.4 ; 1.0)$ & $p>0.999$ \\
\hline \multicolumn{5}{|l|}{ Roland Morris } \\
\hline Baseline and 4 weeks & $2.5(1.4 ; 3.5)$ & $p<0.001$ & $1.6(0.8 ; 2.4)$ & $p=0.001$ \\
\hline Baseline and 8 weeks & $3.6(1.9 ; 5.4)$ & $p<0.001$ & $2.8(1.5 ; 4.0)$ & $p<0.001$ \\
\hline 4 weeks and 8 weeks & $1.2(0.1 ; 2.3)$ & $p=0.225$ & $1.2(0.5 ; 1.9)$ & $p=0.008$ \\
\hline \multicolumn{5}{|l|}{ SF-36 } \\
\hline \multicolumn{5}{|l|}{ Functional capacity } \\
\hline Baseline and 4 weeks & $-5.6(-10.0 ;-1.1)$ & $p=0.084$ & $-6.2(-9.6 ;-2.8)$ & $p=0.002$ \\
\hline Baseline and 8 weeks & $-9.7(-15.6 ;-3.9)$ & $p=0.007$ & $-9.2(-12.4 ;-6.1)$ & $p<0.001$ \\
\hline 4 weeks and 8 weeks & $-4.1(-7.0 ;-1.3)$ & $p=0.028$ & $-3.1(-6.4 ; 0.2)$ & $p=0.402$ \\
\hline \multicolumn{5}{|l|}{ Physical aspects } \\
\hline Baseline and 4 weeks & $-7.4(-18.7 ; 4.0)$ & $p>0.999$ & $-38.5(-57.4-19.5)$ & $p<0.001$ \\
\hline Baseline and 8 weeks & $-25.0(-40.8 ;-9.2)$ & $p=0.011$ & $-42.3(-61.8 ;-22.8)$ & $p<0.001$ \\
\hline 4 weeks and 8 weeks & $-17.6(-29.0 ;-6.3)$ & $p=0.014$ & $-3.8(-16.7 ; 9.0)$ & $p>0.999$ \\
\hline \multicolumn{5}{|l|}{ Pain } \\
\hline Baseline and 4 weeks & $-12.9(-20.2 ;-5.6)$ & $p=0.003$ & $-15.2(-23.1 ;-7.4)$ & $p=0.001$ \\
\hline Baseline and 8 weeks & $-20.5(-28.9 ;-12.0)$ & $p<0.001$ & $-20.0(-30.7 ;-9.3)$ & $p=0.001$ \\
\hline 4 weeks and 8 weeks & $-7.6(-12.2 ;-2.9)$ & $p=0.009$ & $-4.8(-12.7 ; 3.2)$ & $p>0.999$ \\
\hline \multicolumn{5}{|l|}{ Overall health condition } \\
\hline Baseline and 4 weeks & $-2.5(-6.3 ; 1.3)$ & $p>0.999$ & $6.5(-11.9 ;-1.2)$ & $p=0.101$ \\
\hline Baseline and 8 weeks & $-4.2(-8.8 ; 0.5)$ & $p=0.479$ & $-5.0(-12.5 ; 2.5)$ & $p>0.999$ \\
\hline 4 weeks and 8 weeks & $-1.7(-4.4 ; 0.9)$ & $p>0.999$ & $1.5(-13.8 ; 10.8)$ & $p>0.999$ \\
\hline \multicolumn{5}{|l|}{ Vitality } \\
\hline Baseline and 4 weeks & $-6.8(-15.4 ; 1.9)$ & $p=0.746$ & $-3.8(-10.2 ; 2.5)$ & $p>0.999$ \\
\hline Baseline and 8 weeks & $-8.5(-18.0 ; 0.9)$ & $p=0.457$ & $-6.9(-13.6 ;-0.2)$ & $p=0.258$ \\
\hline 4 weeks and 8 weeks & $-1.8(-5.0 ; 1.5)$ & $p>0.999$ & $-3.1(-6.9 ; 0.7)$ & $p=0.661$ \\
\hline \multicolumn{5}{|l|}{ Social aspects } \\
\hline Baseline and 4 weeks & $-2.3(-7.3 ; 2.8)$ & $p>0.999$ & $3.0(-7.1 ; 13.0)$ & $p>0.999$ \\
\hline Baseline and 8 weeks & $-7.4(-15.5 ; 0.7)$ & $p=0.441$ & $0.1(-10.9 ; 11.1)$ & $p>0.999$ \\
\hline 4 weeks and 8 weeks & $-5.1(-9.7 ;-0.6)$ & $p=0.159$ & $-2.9(-12.9 ; 7.2)$ & $p>0.999$ \\
\hline \multicolumn{5}{|l|}{ Emotional aspects } \\
\hline Baseline and 4 weeks & $-7.8(-23.7 ; 8.1)$ & $p>0.999$ & $-5.2(-23.8 ; 13.3)$ & $p>0.999$ \\
\hline Baseline and 8 weeks & $-19.5(-35.9 ;-3.2)$ & $p=0.117$ & $-18.0(-38.9 ; 2.8)$ & $p=0.540$ \\
\hline 4 weeks and 8 weeks & $-11.7(-19.3 ;-4.2)$ & $p=0.014$ & $-12.8(-26.2 ; 0.5)$ & $p=0.359$ \\
\hline \multicolumn{5}{|l|}{ Mental health } \\
\hline Baseline and 4 weeks & $-2.8(-7.9 ; 2.2)$ & $p>0.999$ & $-1.9(-6.9 ; 3.1)$ & $p>0.999$ \\
\hline Baseline and 8 weeks & $-5.9(-9.5 ;-2.2)$ & $p=0.009$ & $-3.8(-9.1 ; 1.6)$ & $p>0.999$ \\
\hline 4 weeks and 8 weeks & $-3.1(-7.4 ; 1.3)$ & $p>0.999$ & $-1.8(-3.9 ; 0.2)$ & $p=0.440$ \\
\hline
\end{tabular}


(RM) for functional capacity, we found evidence of reduction in scores between the initial assessments and week 4 in groups $A(p<0.001)$ and $B(p=0.001)$, between the initial assessments and week 8 in groups $A(p<0.001)$ and B $(p<0.001)$, and between the week 4 and 8 assessments in Group B ( $p=0.008)$ (Table 1).

The analysis of the score progression for SF-36 was described separately for eight domains. Functional capacity: We found evidence of an increase in scores between the initial and week 4 assessments in Group B $(p=0.002)$, between the initial and week 8 assessments in groups $A(p=0.007)$ and $B(p<0.001)$, and between the week 4 and 8 assessments in Group A ( $p=0.028)$. Physical aspects: We found evidence of an increase in scores between the initial assessments and week 4 in Group B $(p<0.001)$, between the initial assessments and week 8 in groups $\mathrm{A}(\mathrm{p}=0.011)$ and $\mathrm{B}(\mathrm{p}<0.001)$, and between week 4 and 8 assessments in Group A ( $p=0.014)$. Pain: We found evidence of an increase in scores between the initial assessments and week 4 in groups $A(p=0.003)$ and $B(p=0.001)$, between the initial assessments and week 8 in groups $A(p<0.001)$ and $B(p=0.001)$, and between the week 4 and 8 assessments in Group $A(p=0.009)$. Overall health condition: We found no evidence of variation in the scores between the assessments in Groups $\mathrm{A}$ ( $\mathrm{p}>0.05$ in all comparisons) and B ( $\mathrm{p}>0.05$ in all comparisons). Vitality: We found no evidence of variation in scores between assessments in Groups A ( $p>0.05$ in all comparisons) and B ( $>0.05$ in all comparisons). Social aspects: We found no evidence of variation in the scores between the assessments in Groups A ( $p>0.05$ in all comparisons) and B ( $p>0.05$ in all comparisons). Emotional aspects: We found evidence of an increase in scores between the week 4 and 8 assessments in Group $\mathrm{A}(\mathrm{p}=0.014)$. Mental health: We found evidence of an increase in scores between the initial and week 8 assessments in Group A ( $p=0.009)$ (Table 1).

We found no evidence of differences when comparing the groups in all three assessments $(p>0.05)$ (Table 2).

\section{DISCUSSION}

It is well established in the Literature that exercise-based treatment for NSCLP is effective. However, there is no consensus on the best models. ${ }^{6,14}$

The study by Chang et al. ${ }^{15}$ showed that exercises focused in strengthening and activation of deep trunk muscles were superior in comparison with other exercises.
TABLE 2. ANALYSIS INSIDE GROUPS: ESTIMATED MEANS AND CONFIDENCE INTERVALS OF 95\% FOR OUTCOMES IN THE INITIAL, WEEK 4, AND WEEK 8 ASSESSMENTS, WITH A COMPARISON BETWEEN GROUPS

\begin{tabular}{|c|c|c|}
\hline Variables & $\begin{array}{l}\text { Group A vs. Group } \\
\text { B }\end{array}$ & p \\
\hline \multicolumn{3}{|l|}{ PNRS } \\
\hline Baseline & $0.4(-1.9 ; 1.2)$ & $p>0.999$ \\
\hline 4 weeks & $-1.2(-2.7 ; 0.4)$ & $p=0.408$ \\
\hline 8 weeks & $-0.9(-2.3 ; 0.5)$ & $p=0.655$ \\
\hline \multicolumn{3}{|c|}{ Roland Morris } \\
\hline Baseline & $-1.1(-5.0 ; 2.8)$ & $p>0.999$ \\
\hline 4 weeks & $-0.3(-3.9 ; 3.4)$ & $p>0.999$ \\
\hline 8 weeks & $-0.2(-3.8 ; 3.3)$ & $p>0.999$ \\
\hline \multicolumn{3}{|l|}{ SF-36 } \\
\hline
\end{tabular}

\begin{tabular}{|c|c|c|}
\hline Functional capacity & & \\
\hline Baseline & $3.3(-10.5 ; 17.1)$ & $p>0.999$ \\
\hline 4 weeks & $3.9(-8.5 ; 16.3)$ & $p>0.999$ \\
\hline 8 weeks & $2.9(-9.4 ; 15.1)$ & $p>0.999$ \\
\hline \multicolumn{3}{|l|}{ Physical aspects } \\
\hline Baseline & $-18.2(-45.1 ; 8.7)$ & $p=0.554$ \\
\hline 4 weeks & $12.9(-13.6 ; 39.4)$ & $p>0.999$ \\
\hline 8 weeks & $-0.9(-24.6 ; 22.8)$ & $p>0.999$ \\
\hline \multicolumn{3}{|l|}{ Pain } \\
\hline Baseline & $9.8(-6.5 ; 26.0)$ & $p=0.714$ \\
\hline 4 weeks & $12.1(-3.1 ; 27.3)$ & $p=0.355$ \\
\hline 8 weeks & $9.3(-5.8 ; 24.4)$ & $p=0.682$ \\
\hline \multicolumn{3}{|c|}{ Overall health condition } \\
\hline Baseline & $-2.3(-13.0 ; 8.4)$ & $p>0.999$ \\
\hline 4 weeks & $1.8(-9.0 ; 12.5)$ & $p>0.999$ \\
\hline 8 weeks & $-1.5(-13.8 ; 10.8)$ & $p>0.999$ \\
\hline \multicolumn{3}{|l|}{ Vitality } \\
\hline Baseline & $0.5(-14.3 ; 13.4)$ & $p>0.999$ \\
\hline 4 weeks & $-3.4(-15.6 ; 8.8)$ & $p>0.999$ \\
\hline 8 weeks & $-2.1(-14.3 ; 10.2)$ & $p>0.999$ \\
\hline \multicolumn{3}{|l|}{ Social aspects } \\
\hline Baseline & $3.2(-11.2 ; 17.7)$ & $p>0.999$ \\
\hline 4 weeks & $-2.0(-17.6 ; 13.6)$ & $p>0.999$ \\
\hline 8 weeks & $-4.3(-18.2 ; 9.7)$ & $p>0.999$ \\
\hline \multicolumn{3}{|l|}{ Emotional aspects } \\
\hline Baseline & $0.6(-23.7 ; 24.9)$ & $p>0.999$ \\
\hline 4 weeks & $-2.0(-25.8 ; 21.8)$ & $p>0.999$ \\
\hline 8 weeks & $-0.9(-20.9 ; 19.1)$ & $p>0.999$ \\
\hline \multicolumn{3}{|l|}{ Mental health } \\
\hline Baseline & $0.4(-9.3 ; 10.1$ & $p>0.999$ \\
\hline 4 weeks & $-0.5(-12.2 ; 11.2)$ & $p>0.999$ \\
\hline 8 weeks & $-1.7(-12.6 ; 9.2)$ & $p>0.999$ \\
\hline
\end{tabular}

Estimated mean differences and confidence intervals of 95\%. PNRS: Pain Numerical Rating Scale 
The selection of exercises for this study also took into account their applicability in a home environment, simplicity, and focus on activating the deep trunk muscles, as shown in the electromyography-based study by Okubo et al. ${ }^{16}$

Of the targeted muscles, the rotatores, which are directly connected to each vertebral segment, the transverse abdominal muscle, and the internal oblique, which provide segmental stabilization to the spine during contraction, are considered primary stabilizers. These muscles act in synergy, forming a co-contraction mechanism; thus, allowing the individual to be prepared to handle impact during functional activities without overloading the adjacent structures. ${ }^{17,18}$

The choice of the age range for participants (18-65 years old), as well as the indifference regarding gender, was based in similar previous studies and had no influence on the treatment prescribed. ${ }^{19-21}$ Some participants, especially the older ones, found it difficult to carry out some exercises. In those cases, they were instructed to follow an adapted version of the exercise.

Confirming the finding previously described on home exercise programs, the booklet and low complexity of exercises seemed to contribute to a zero abandonment throughout the eight weeks.,9,22

Individuals in Group A were less disciplined regarding the number of sessions carried out, showing that the weekly assistance and guidance of the physical therapist were important to improve adhesion to the program. However, there was no significant difference in the comparison between groups, indicating the effectiveness of unsupervised exercise therapy.

There is no recommendation concerning the ideal duration of an exercise program for NSCLP treatment. ${ }^{6,14}$ Our study found significant improvement when comparing most of the initial parameters with those from week 4 and 8 ; however, that was not what happened in the comparison between week 4 and 8 , indicating a stabilization of the parameters. Medium and long-term follow up of these patients will help determine the duration of improvement, in addition to verifying if participants will continue to carry out the exercises on their own.

The study assessed the effect of home exercise programs in NSCLP comparing initial parameters with those from week 4 and 8 . Other studies have shown the advantages of home exercise programs in comparison to other types of therapy, such as the use of anti-inflammatory drugs. ${ }^{14,23}$

The method used to analyze the improvement of symptoms was based on self-administered questionnaires. Studies that used ultrasound and electromyography to assess hypertrophy and activation of trunk muscles after exercises also found positive results. ${ }^{24}$

Low back pain is an extremely common problem that affects around $70 \%$ of the adult population and represents the second most frequent reason for seeking medical assistance. It needs to be seen as a public health issue, and it is of the utmost importance for general physicians or specialists, to know how to treat and guide these patients adequately. ${ }^{25}$

The improvement in levels of pain, functional capacity, and quality of life obtained from home exercise programs confirm the theory that cases of NSCLP with lower complexity can be treated and prevented in Basic Health Units. They do not require complex facilities or continuous supervision by a physical therapist, so other health professionals, with adequate training, can apply exercise therapy, lowering costs and preventing an overload of secondary rehabilitation centers, which then would be able to focus in more severe cases, such as of patients with neurological deficit and post-operative. ${ }^{7}$

Individuals with time restrictions or difficulty in traveling to physical therapy centers can also benefit from partially-supervised rehabilitation programs, provided they have some instrument to guide them during treatment.

\section{Study limitations}

It was not possible to blind the physical therapist that supervised the Group B sessions, nor to randomize the grouping of individuals, due to the nature of the intervention and availability of participants. Furthermore, the participants were responsible for controlling the frequency of sessions, which generates a risk of bias.

\section{CONCLUSION}

Therapy through home exercise programs, when conducted for 8 weeks, with the assistance of a booklet, was effective for improving levels of pain, functional capacity, and quality of life, in patients with NSCLP. The weekly supervision by the physical therapist had no significant impact on the final results when comparing both groups. 


\section{RESUMO:}

OBJETIVO: Avaliar dor, capacidade funcional e qualidade de vida de pacientes com dor lombar crônica inespecífica após terapia por exercícios domiciliares, com diferentes maneiras de supervisão.

MÉTODO: Trinta indivíduos de ambos os sexos, com idade entre 18 e 65 anos, apresentando dor lombar crônica inespecífica, realizaram os exercícios propostos três vezes por semana, durante oito semanas. Indivíduos do Grupo $A(N=17)$ realizaram os exercícios após única sessão supervisionada. Já os indivíduos do Grupo B ( $N=13)$ foram supervisionados uma vez por semana no centro de reabilitação. Ambos receberam cartilha com orientações e questionários para avaliar dor, capacidade funcional e qualidade de vida; durante avaliação inicial, após quatro e oito semanas.

RESULTADOS: Houve melhora da dor e capacidade funcional entre as avaliações inicial e semana 4, e inicial e semana 8 nos dois grupos $(p<0,05)$. Na avaliação de qualidade de vida (SF-36), os critérios de dor, capacidade funcional e aspectos físicos obtiveram melhora significativa após oito semanas ( $p<0,05)$. Não houve diferença significativa ao comparar os grupos $(p>0,05)$.

CONCLUSÃo: A terapia por exercícios domiciliares, quando realizada num período de oito semanas, com auxílio da cartilha, foi eficaz para melhora da dor, capacidade funcional e qualidade de vida, em pacientes com dor lombar crônica inespecífica. A supervisão semanal não influenciou de forma significativa o resultado final quando comparados os grupos.

PALAVRAS-CHAVE: Dor lombar. Terapia por exercício. Músculos paraespinais. Músculos abdominais.

\section{REFERENCES}

1. Deyo RA, Weinstein JN. Low back pain. N Eng| J Med. 2001;344(5):363-70

2. Waddell G. The back pain revolution. $2^{\text {nd }}$ ed. Philadelphia: Churchill Livingstone; 2004.

3. Hodges PW, Richardson CA. Inefficient muscular stabilization of the lumbar spine associated with low back pain. A motor control evaluation of transversus abdominis. Spine. 1996;21(22):2640-50.

4. Hodges PW, Richardson CA. Altered trunk muscle recruitment in people with low back pain with upper limb movement at different speeds. Arch Phys Med Rehabil. 1999;80(9):1005-12.

5. van Dieën JH, Selen LP, Cholewicki J. Trunk muscle activation in lowback pain patients, an analysis of the literature. J Electromyogr Kinesiol. 2003;13(4):333-51.

6. Airaksinen O, Brox JI, Cedraschi C, Hildebrandt J, Klaber-Moffett J, Kovacs F, et al; COST B13 Working Group on Guidelines for Chronic Low Back Pain. European guidelines for the management of chronic nonspecific low back pain. Eur Spine J. 2006;15(Suppl 2):S192-300.

7. Ferrer MLP, Silva AS, Silva IRK, Padula RS. Microrregulation of access to the care network in physiotherapy: strategies for improving the care flow in a secondary care service. Fisioter Pesqui. 2015;22(3):223-30.

8. Escolar-Reina P, Medina-Mirapeix F, Gascón-Cánovas II, Montila-Herrador J, Jimeno-Serrano FJ, Oliveira Sousa SL, et al. How do care-provider and home exercise program characteristics affect patient adherence in chronic neck and back pain: a qualitative study. BMC Health Serv Res. 2010;10:60

9. Palazzo C, Klinger E, Dorner V, Kadri A, Thierry O, Boumenir Y, et al. Barriers to home-based exercise program adherence with chronic low back pain: patient expectations regarding new technologies. Ann Phys Rehabil Med. 2016;59(2):107-13.

10. Chow SC, Wang H, Shao I. Sample size calculations in clinical research. Boca Raton: Taylor \& Francis;2003. p.48-50.

11. Nusbaum L, Natour J, Ferraz MB, Goldenberg |. Translation, adaptation and validation of the Roland Morris questionnaire: Brazil Roland-Morris. Braz f Med Biol Res. 2001;34(2):203-10.

12. Ciconelli RM, Ferraz MB, Santos W, Meinão I, Quaresma MR. Tradução para a língua portuguesa e validação do questionário genérico de qualidade de vida SF-36 (Brasil SF-360. Rev Bras Reumatol. 1999;39(3):143-50.

13. Guimarães LSP, Hirakata VN. Uso do modelo de equações de estimativas generalizadas na análise de dados longitudinais. Rev HCPA[Internet]. 2012;32(4):503-11.

14. Searle A, Spink M, Ho A, Chuter V. Exercise interventions for the treat- ment of chronic low back pain: a systematic review and meta-analysis of randomised controlled trials. Clin Rehabil. 2015;29(12):1155-67.

15. Chang WD, Lin HY, Lai PT. Core strength training for patients with chronic low back pain. J Phys Ther Sci. 2015;27(3):619-22.

16. Okubo Y, Kaneoka K, Imai A, Shiina I, Tatsumura M, Izumi S, et al. Electromyographic analysis of transversus abdominis and lumbar multifidus using wire electrodes during lumbar stabilization exercises. | Orthop Sports Phys Ther. 2010;40(11):743-50.

17. Aquino CF, Viana SO, Fonseca ST, Bricio RS, Vaz DV. Mecanismos neuromusculares de controle da estabilidade articular. R Bras Ci e Mov. 2004;12(2):35-42.

18. Ferreira PH, Ferreira ML, Maher CG, Refshauge K, Herbert RD, Hodges PW. Changes in recruitment of transversus abdominis correlate with disability in people with chronic low back pain. Br J Sports Med. 2010;44(16):1166-72.

19. Magalhaes MO, França FJ, Burke TN, Ramos LA, Carvalho e Silva APMC, Almeida GP, et al. Efficacy of graded activity versus supervised exercises in patients with chronic non-specific low back pain: protocol of a randomised controlled trial. BMC Musculoskelet Disord. 2013;14:36.

20. O'Keeffe M, Purtill H, Kennedy N, O'Sullivan P, Dankaerts W, Tighe A, et al. Individualised cognitive functional therapy compared with a combined exercise and pain education class for patients with non-specific chronic low back pain: study protocol for a multicentre randomised controlled trial. BMJ Open. 2015;5(6):e007156

21. van Middelkoop M, Rubinstein $S M$, Kuijpers $T$, Verhagen $A P$, Ostelo $R$, Koes BW, et al. A systematic review on the effectiveness of physical and rehabilitation interventions for chronic non-specific low back pain. Eur Spine J. 2011;20(1):19-39.

22. Díaz-Cerrillo JL, Rondón-Ramos A. Design of an educational tool for Primary Care patients with chronic non-specific low back pain. Aten Primaria. 2015;47(2):117-23.

23. Shirado O, Doi T, Akai M, Hoshino Y, Fujino K, Hayashi K, et al; Japan Low back-pain Exercise Therapy Study; Investigators Japanese Orthopaedic Association; Japanese Society for Musculoskeletal Rehabilitation; |apanese Clinical Orthopaedic Association. Multicenter randomized controlled trial to evaluate the effect of home-based exercise on patients with chronic low back pain: the Japan low back pain exercise therapy study. Spine. 2010;35(17):E811-9.

24. Yang HS, Lee YS, Jin SA. Effect of evidence-based trunk stability exercises on the thickness of the trunk muscles. J Phys Ther Sci. 2015;27(2):473-5.

25. Cypress BK. Characteristics of physician visits for back symptoms: a national perspective. Am J Public Health. 1983;73(4):389-95. 